Rev. Elet. em Gestão, Educação e Tecnologia Ambiental (e-ISSN: 2236-1170)

\title{
QUALIDADE AMBIENTAL E SANITÁRIA DAS INDÚSTRIAS DE LATICÍNIOS DO MUNICÍPIO DE MOSSORÓ-RN
}

\author{
Jerônimo, C. E. M. ${ }^{1}$, Coelho, M. S. ${ }^{2}$, Moura, F. N. ${ }^{3}$, Araujo, A. B. A. ${ }^{4}$ \\ ${ }^{1}$ Universidade Potiguar. Petróleo Brasileiro S/A. Sede Cidade da Esperança. E-mail: $\underline{c}$ _enrique@ hotmail.com \\ ${ }^{2}$ UNI-NILTON LINS. E-mail: mateusscoelho@hotmail.com \\ ${ }^{3}$ UFERSA. E-mail: fernandanegreiros17@hotmail.com \\ ${ }^{4}$ UERN. E-mail: beatriz_ufersa@hotmail.com
}

\section{RESUMO}

A atividade do processamento de derivados do leite se constitui como uma das principais atividades industriais da agroindústria brasileira. No estado do Rio Grande do Norte essa atividade se apresenta com grande representatividade, em especial pelo apoio dado a programação de erradicação da pobreza, gerenciados pelos governos federais e estaduais. Entretanto, apesar da grande importância econômica e social, não são aferidos os riscos e impactos ambientais associados a tais atividades. Sendo assim, neste trabalho foi realizado um diagnostico nas principais empresas da região, de forma a identificar as principais atitudes nocivas ao meio ambiente. A metodologia aplicada consistiu no preenchimento in loco de um questionário desenvolvido com o intuito de avaliar as questões ambientais relativas: ao processo produtivo, aos parâmetros de balanço de material e as oportunidade redução na fonte. As empresas analisadas foram as instaladas do município de Mossoró-RN, principal cidade do estado (excetuando-se a capital). Constatou-se que as emissões atmosféricas representam a principal fonte de poluição nestas indústrias, apesar do pequeno porte das caldeiras e ao fato de que a maioria das indústrias se situa na periferia do município ou na zona rural. Com relação aos resíduos líquidos, os mesmos se apresentam em pequena quantidade, e com destinações adequadas dadas as dimensões dos estabelecimentos. Constatou-se, também, que nenhuma das empresas possui um programa de coleta seletiva de resíduos.

PALAVRAS-CHAVE: Gestão ambiental; tratamento de resíduos; emissões atmosféricas; laticínios.

\section{ABSTRACT}

The activity of the processing of dairy products constitutes one of the main industrial activities of the Brazilian agribusiness. In the state of Rio Grande do Norte this activity is presented with a large representation, in particular the support given to poverty eradication program, managed by federal and state governments. However, despite the great economic and social importance, are not assessed the risks and environmental impacts associated with such activities. Thus, this work was a major diagnostic companies in the region in order to identify the key attitudes harmful to the environment. The methodology consisted in filling the spot of a questionnaire developed in order to assess the environmental issues: the production process, the parameters of the material balance and the source reduction opportunity. The companies analyzed were installed in the Mossoró-RN, the main city in the state (except the capital). It was found that air emissions are the major source of pollution in these industries, despite the small size of the boilers and the fact that most industries are located on the outskirts of the city or the countryside. With regard to liquid 
Rev. Elet. em Gestão, Educação e Tecnologia Ambiental (e-ISSN: 2236-1170)

waste, they are present in small amounts, and destinations appropriate given the size of establishments. It was noted also that neither company has a program of selective collection of waste.

KEYWORDS: Environmental management, waste treatment, air emissions, dairy.

\section{INTRODUÇÃO}

Os laticínios, segundo Carvalho (2010), são os produtos comestíveis que possui o leite como principal elemento em sua composição ou qualquer produto dessa atividade industrial. Entre esses produtos são considerados como laticínios: o leite pasteurizado, o leite desnatado, os queijos, os cremes de leite, a manteiga, o leite condensado, o doce de leite, o iogurte, as bebidas fermentadas, os sorvetes dentre outros.

Por ser um alimento natural completo, rico em macro e micronutrientes, o leite constituise em um ótimo alimento não só para o homem, mas também para uma infinidade de microorganismos. Sob o ponto de vista tecnológico, os microorganismos mais importantes são aqueles que contaminam o leite após a ordenha, provenientes dos equipamentos e utensílios utilizados e de contaminações pelo ar. Daí a importância de um bom controle sanitário nas atividades que manipulam tal produto.

A qualidade do leite cru está intimamente relacionada com o grau de contaminação inicial, conforme cita EMBRAPA (2012), e com a temperatura e o tempo em que o leite permanece estocado até a pasteurização. Em decorrência de vários fatores, entre eles o aumento da competitividade devido à entrada de empresas de grande porte que necessitam de ganho em escala e exigem uma melhor qualidade da matéria prima, o setor leiteiro brasileiro vem passando por várias transformações.

Segundo Carvalho (2012) o leite cru é um veículo perigoso de microorganismos patogênicos ao homem. Nem sempre a contaminação resulta em mudanças nas características organolépticas do leite, razão pela qual é tão importante o controle das condições de higiene à que o produto é submetido.

São três os subprodutos gerados pelas indústrias de laticínios sob a forma de efluente industrial: o soro, o leitelho (na desleitagem, onde há a retirada da parte líquida do creme batido, conforme descrevem Vogelaar (1997) e Jerônimo (2003). Esse líquido é denominado leitelho e, após um processo bem feito, apresenta-se de cor azulada). E o leite ácido. Destes, o primeiro é o de maior importância, tanto pelo volume produzido (cerca de $9 \mathrm{~L}$ por $\mathrm{Kg}$ de queijo produzido) e pela própria característica de matéria-prima de qualidade e de amplo espectro de possibilidades de reutilização, quanto pelo seu enorme poder poluente.

O setor do leite no Brasil é um dos mais importantes dentre as atividades agroindustriais, tanto no aspecto econômico quanto no social. É um segmento industrial bastante diversificado no âmbito nacional; encontrando-se presente nos mesmos, empresas de laticínios de diversos portes, variando de empresas ditas de fundo de quintal (beneficiadoras de volumes reduzidos de Leite) até grandes multinacionais e cooperativas centrais capazes de processar um montante diário de centenas de milhares de litros de leite, conforme cita Gomes (2012).

De acordo com o IBGE, a região nordeste é a terceira maior produtora de leite do Brasil, onde o RN é portador da média de um laticínio por cidade, que pelo menos movimenta uma economia de US\$ 5.000,00/mês (SEBRAE, 2002). Estima-se em cerca de 2000 laticínios/queijeiras 
Rev. Elet. em Gestão, Educação e Tecnologia Ambiental (e-ISSN: 2236-1170)

atuando no Rio Grande do Norte. Tendo uma participação significativa nesse montante. Na cidade de Mossoró, localizada no oeste potiguar, que possui 213.841 habitantes (IBGE, 2011), tem-se cerca de seis laticínios, dois se encontrando na periferia da cidade, dois em área urbana pouco habitada e dois outros na zona rural. Porém, neste trabalho serão avaliados grandes consumidores de leite, tais como, fábricas de sorvetes, iogurtes e queijos.

Observando as questões supracitadas percebe-se que o setor agroindustrial de leite no Brasil tem uma forte relação com a poluição ambiental, pois se apresenta como uma atividade industrial e têm sido incrementados com novas tecnologias de controle nos últimos anos, em especial, como processos com tecnologias mais limpas; conforme descrevem Jerônimo (2003) e Rohlfes et al (2011). Sendo assim, necessita-se um rigor no controle ambiental e desenvolvimento de ações de gerenciamento que permitam um controle efetivo dos aspectos e impactos ambientais associados.

Neste trabalho foi realizado um levantamento dos aspectos críticos que envolvem as questões sanitárias e ambientais dos laticínios localizados no município de Mossoró, estado do Rio Grande do Norte. Tendo-se como objetivos mapear os pontos fortes e fracos para proposição de um modelo de gerenciamento ambiental e sanitário adequado a legislação vigente e boas práticas de fabricação dos derivados do leite.

\section{MATERIAIS E MÉTODOS}

O estudo foi realizado mediante visitas técnicas, realizadas nas indústrias de laticínios da cidade. As finalidades das visitas foram o conhecimento da situação tecnológica, ambiental e a identificação dos pontos críticos nas demais etapas do projeto (estudo de alternativas tecnológicas para o processo industrial e estudo de alternativas para o tratamento de efluentes).

Os dados necessários à elaboração do diagnóstico foram obtidos mediante a aplicação de um questionário nas indústrias de laticínios participantes do projeto. Trabalhou-se com informações e dados secundários fornecidos diretamente pelas indústrias.

Para dimensionamento do universo a ser pesquisado definiu-se uma amostra representativa da cidade de Mossoró, para realizar o estudo de impactos ao meio ambiente. Os estabelecimentos onde se procederam as coletas de dados foram escolhidos por meio de uma pesquisa e localização. Definiu-se o tamanho da amostra (n) e o número de estabelecimentos relacionados $(\mathrm{N})$. Para a escolha sistemática dos estabelecimentos avaliados, foram adotados intervalos de três vezes a constante $\mathrm{K}$, sendo $\mathrm{K}$ o número inteiro mais próximo de $\mathrm{N} / \mathrm{n}$. Para a escolha sistemática dos estabelecimentos avaliados, foram listados todos os estabelecimentos credenciados em entidades como: Sindicato dos Laticínios/RN, SEBRAE/RN e FIERN; quantificando o parâmetro N. O tamanho da amostra ( $n$ ) foi definido como 12. Assim a escolha dos estabelecimentos obedeceu a seqüência: $3 k, 3 k+k, \ldots+3 k+n k$. Quando não foi possível obter os dados do estabelecimento selecionado, escolheu-se através da seqüência: $3 k+(n+1) k, \ldots$ Até $3 k+(n+5) k$.

No desenvolvimento da pesquisa foram descritas características que diferenciam a empresa nos aspectos ambientais, sejam eles positivos ou negativos (consumo de água, energia elétrica etc). Foi descritas também a respeito da localização da empresa, a sua realidade e importância para a qualidade ambiental da localidade. Os pontos a serem avaliados foram baseados na metodologia aplicada por Saraiva; Pereira (2009).

As informações levantadas no trabalho de campo foram todas tabuladas em forma de Banco de Dados. Todos os dados coletados foram tratados dando um enfoque principal aos 
Rev. Elet. em Gestão, Educação e Tecnologia Ambiental (e-ISSN: 2236-1170)

principais efeitos impactantes ao meio ambiente, de forma que pudessem ser comparados e qualificados quanto ao grau de nocividade causada ao mesmo. Com o diagnóstico, foi possível apontar as principais falhas do sistema de gestão hoje existente, bem como, levantar uma matriz de soluções para a minimização desses impactos, referenciadas na adequação de normas internacionais já existentes.

As informações obtidas com o preenchimento dos questionários desenvolvidos foram subdivididas em quatro etapas seqüenciais. Dentre os itens contemplados no questionário uma síntese é mostrada na Figura 1.

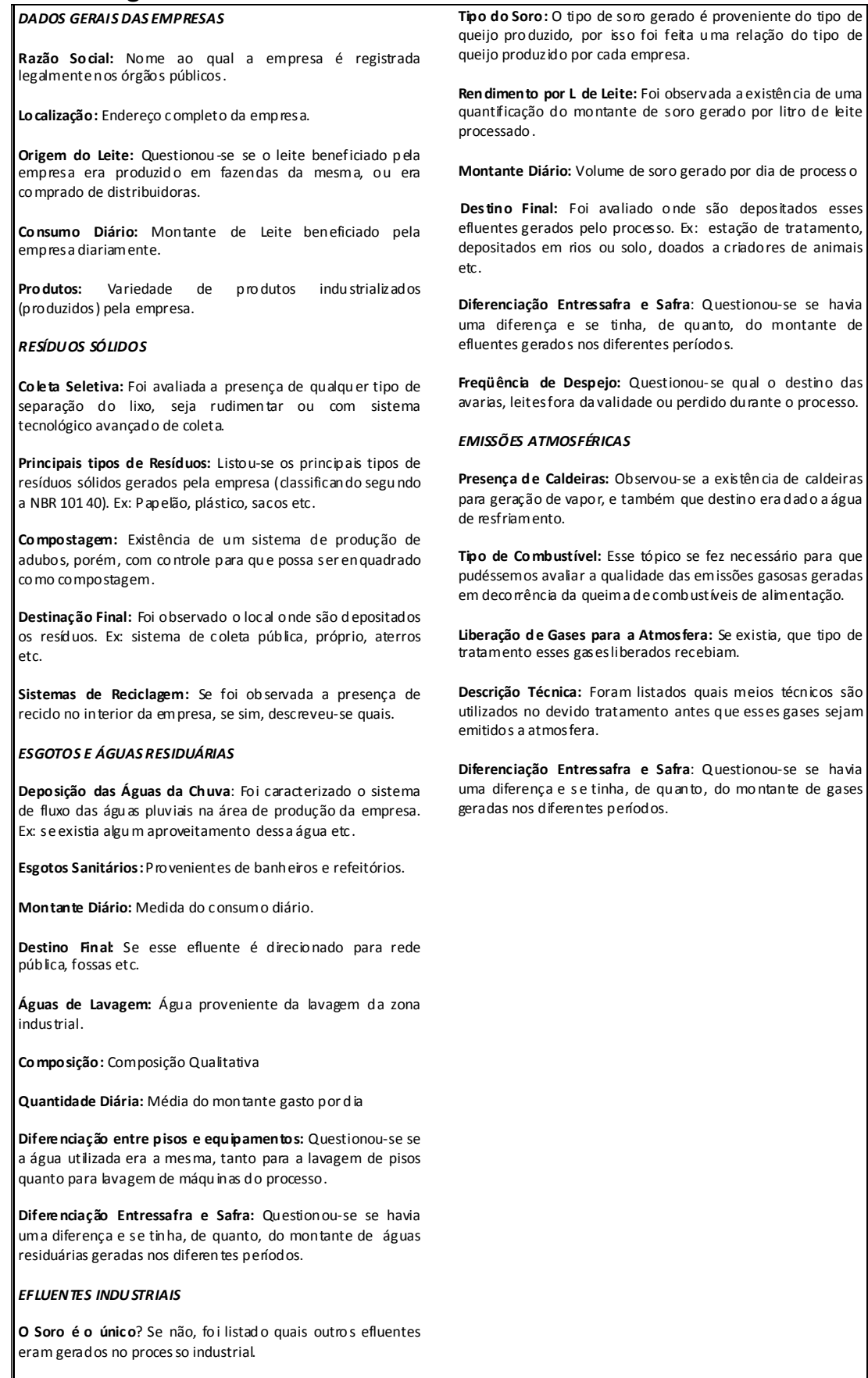

Figura 1. Questionário utilizado para levantamento de dados. 
Rev. Elet. em Gestão, Educação e Tecnologia Ambiental (e-ISSN: 2236-1170)

\section{RESULTADOS E DISCUSSÕES}

A natureza e abrangência das informações coletadas permitiram análises que abordaram diversos temas importantes para o setor de laticínios, tais como capacidade de recepção e processamento de leite, produtos fabricados, limpeza e desinfecção, situação junto ao SIF (Serviço de Inspeção Federal), geração de empregos, consumo de energia e abastecimento de água (fontes de abastecimento, tratamento da água, consumo de água).

Observou-se nas visitas que existia uma diferenciação entre as empresas localizadas nas zonas rural e urbana da cidade, principalmente no que diz respeito ao local e formas de disposição final dos resíduos sólidos e efluentes líquidos. Tal comportamento já era observado por SEBRAE (1997), em avaliação de laticínios do estado de Minas Gerais.

Uma das empresas localizada na zona urbana utiliza o sistema de disposição público para coleta de resíduos sólidos e esgotamento sanitário. No caso das empresas na área rural, os resíduos sólidos são dispostos em lixões próprios, sem qualquer forma de tratamento (Ex: impermeabilização) e queimados.

Quanto aos efluentes são em sua maioria dispostos na rede de esgoto da cidade ou em lagoa de captação particular para os efluentes industriais.

A totalidade dos laticínios da cidade de Mossoró estão em funcionamento e sem a fiscalização dos órgãos competentes no que se refere ao meio ambiente.

\subsection{Descrição Geral das Empresas Pesquisadas}

Foram visitadas doze empresas de pequeno porte, tratando-se de organizações beneficiadoras ou consumidoras de 600 até $10.000 \mathrm{~L}$ de leite diariamente, onde em sua grande maioria eram produtoras do próprio leite; perfil semelhante ao descrito por SEBRAE (2002).

As empresas localizadas na zona rural, não sofrem qualquer tipo de cobrança ou fiscalização por parte do órgão de fiscalização ambiental. Permitindo assim, qualquer tipo de procedimento clandestino por parte do laticínio.

\subsection{Gerenciamento dos Resíduos Sólidos}

A constituição dos resíduos sólidos gerados nas indústrias de laticínios visitadas, embora sendo em pequena quantidade, é muito variada, variação esta função da linha de produção. Os principais resíduos produzidos são: embalagens plásticas, embalagens de papel, cinzas de caldeira, aparas de queijo, gorduras e lixo doméstico.

As empresas visitadas não apresentam coleta seletiva e nem dispõe de sistema público de coleta para aquelas que estão localizadas na zona rural. O resíduo gerado é lançado direto em aterros e queimados sem qualquer sistema de fiscalização ou controle. Já a empresa que dispõe do sistema público, esse resíduo segue o mesmo destino do doméstico, que também é disposto em aterros e lixões, sem qualquer seleção ou controle.

Pôde-se analisar, porém que, em sua totalidade, não apresentam sistema algum de reciclagem interna de resíduos gerados. Com exceção da empresa da zona rural que possui o compromisso de entregar ao fornecedor do tubo da bobina de um dos equipamentos, o tubo já utilizado para que seja reciclado, pela empresa fornecedora, não sendo iniciativa do laticínio. No geral não disponibilizam de dado algum que implique no controle do montante global de resíduos. 
Rev. Elet. em Gestão, Educação e Tecnologia Ambiental (e-ISSN: 2236-1170)

\subsection{Esgotamento Sanitário e Águas Residuárias}

Nenhuma das empresas visitadas era dotada de algum tipo de sistema pluvial alternativo para que houvesse o aproveitamento ou destino selecionado das águas, todas as empresas adotavam como sistema de deposição das águas da chuva a infiltração natural.

Quanto aos esgotos sanitários, nenhum laticínio tinha conhecimento do montante diário ou mensal que se é destinado a esses fins. No tocante a destinação final, a empresa localizada na zona rural ou urbana não dotada de sistema de saneamento, depositam seus efluentes sanitários em fossas sépticas sem qualquer tratamento prévio.

A grande maioria delas não possuía, assim como para os resíduos sólidos, sistema de gerenciamento de águas residuais e sanitárias, sendo essa realidade observada para outros segmentos e na própria gestão publica de pequenos municípios, como descrevem Jerônimo; Santiago Jr (2012) para um outro município do estado do Rio Grande do Norte.

Apesar de quantificarem a água de lavagem (lavagem e desinfecção de equipamentos, lavagem de ambientes, principalmente dos pisos; quebra de embalagens contendo leite; e perdas nas máquinas e lubrificação dos transportadores), nenhuma destina essa água a um sistema de tratamento antes da disposição ao meio ambiente. Já que essa água está em geral contaminada com componentes químicos como Cloro, Soda Cáustica, Detergentes, CIP (Hidróxido de sódio, Àcido Nítrico, água).

Nas empresas localizadas na área urbana, essa água de lavagem é lançada direto no sistema público de esgotos sem qualquer tratamento.

\subsection{Efluentes Industriais}

O principal efluente industrial, apresentado pelos laticínios é o soro. Soro este, proveniente do queijo tipo Ricota, único produzido que dispensa soro para o meio, já que este soro é subproduto da produção de queijo de coalho, sendo aproveitado para esta produção, conforme descrevem Maragno; Campos (1992) e Coldebella et al (2010).

Na produção de queijo é gerado em média um volume de $9 \mathrm{~L}$ de soro como subproduto por quilograma de queijo produzido. Dessa maneira, a geração de soro de um laticínio vai variar proporcionalmente com sua capacidade produtiva.

Foi observado, que um produtor situado na zona urbana dispõe seus efluentes industriais (soro) na rede pública de esgoto, pois não possuem mercado para vender a criadores de suínos na região. Já um dos localizados na zona rural, não possuem esse tipo de efluente.

A perda de leite no processo produtivo é quase inexistente em quase todos os laticínios devido à vasta aplicabilidade dessa matéria-prima. Todo o leite que retorna as empresas (avaria) é destinado, na empresa urbana para a produção de queijo de manteiga, já a empresa rural conduz esse material à pocilga da fazenda da empresa.

\subsection{Emissões Atmosféricas}

Foi observada a presença de caldeiras, nas empresas visitadas pela equipe técnica, no entanto não foi encontrado nenhum sistema de tratamento para os gases liberados.

O tipo de combustível de alimentação utilizados nessas caldeiras é principalmente a madeira. No entanto, foi constatada a preocupação de alterar o combustível por razões diferente: 
Rev. Elet. em Gestão, Educação e Tecnologia Ambiental (e-ISSN: 2236-1170)

na empresa urbana a preocupação em diminuir a utilização da madeira se deu realmente pela preocupação ambiental de não mais incentivar o corte de árvores, sendo utilizada lá inclusive uma placa de captação de energia solar para pré-aquecer a água utilizada para o vapor na caldeira. As duas empresas são privilegiadas pelo fato de existir em região próxima produção de castanha em larga escala, produzindo a assim grande quantidade de casca da mesma, sendo este material utilizado pelas duas empresas como combustível alternativo para as caldeiras.

No entanto, a razão pela qual uma das empresas da área urbana substituiu seu combustível pela casca da castanha para alimentação da caldeira é a redução de custos com um óleo utilizado anteriormente alternado com a madeira. O resultado final é positivo, pois nos casos de substituição os gases que passam a ser emitidos são menos prejudiciais; tal cenário foi observado também por Prince (1999).

Em decorrência da presença dessas caldeiras a liberação de gases é um aspecto ambiental imprescindível de controle. Os gases são, evidentemente, poluentes por serem provenientes da queima principalmente de madeira. Segundo as normas de poluição ambiental esses gases devem ser tratados antes de liberados a atmosfera, exigência não respeitada pelas empresas.

\section{CONCLUSÕES}

Em linhas gerais, puderam-se observar pequenas distinções entre as empresas localizadas nas zonas rural e urbana da cidade, especialmente em relação às formas de disposição final dos resíduos sólidos e efluentes líquidos.

No que se refere aos efluentes líquidos, observou-se que o problema é a destinação final dada à fração não aproveitada do soro, que possui destino final não exatamente correto, já que um é enviado à rede de esgoto pública, não sabendo, portanto se é feito o tratamento correto desse tipo de resíduos, já que a rede pública recolhe todos os tipos de resíduos de variadas origens, não existindo controle específico, no outro caso os resíduos industriais são depositados em lagoa própria, e como houve resistência à vistoria da nossa equipe, não podemos assegurar esta foi construída adequadamente, de acordo com as normas técnicas específicas, e caso esteja irregular, esta polui diuturnamente o solo e o subsolo dessa área.

Em relação aos resíduos sólidos constatou-se, pelos dados obtidos, que este setor industrial apresenta (a exemplo de outros que atuam no Brasil) grande carência de dados quantitativos e qualitativos de geração dos mesmos. Como o volume de resíduos sólidos nesse setor é geralmente baixo, soluções cômodas e simples de disposição final têm sido adotadas, sem a utilização de critérios técnicos, podendo significar perdas econômicas e agressões ao meio ambiente.

Referenciando-se as emissões gasosas, pelo porte das caldeiras presenciadas, não é de se esperar para a maioria dos laticínios a ocorrência de problemas no que se refere às emissões atmosféricas, desde que se garantida a adequada operação e manutenção desses equipamentos de geração de vapor.

Observou-se, também, que em uma das empresas utiliza-se de caldeira a lenha. O que contribuem para a melhoria do cenário, tendo em vista o menor teor de enxofre presente na lenha em relação aos óleos comuns torna as emissões menos agressivas pontualmente, contudo, o problema gerado pela devastação de áreas inadequadas e o tráfico de lenha colocam um contraponto e auxiliam a complexar esse sistema.

É preocupante, também, o fato de que a grande maioria dos laticínios que usam a lenha como combustível não dispõem de adequadas condições de armazenamento dessa lenha de 
Rev. Elet. em Gestão, Educação e Tecnologia Ambiental (e-ISSN: 2236-1170)

alimentação, de modo a garantir que esta esteja permanentemente seca, o que é fundamental inclusive para a minimização da emissão de material particulado. O fato de que a maioria das caldeiras estarem localizadas na zona rural ou periferia das cidades torna-se mais um fator amenizante em relação as vizinhanças.

\section{REFERÊNCIAS}

CARVALHO, G. R. A indústria de laticínios no Brasil: passado, presente e futuro. Acessivel em: http://marcosveterinario.blogspot.com.br/2011/04/industria-de-laticinios-no-brasil.html\#!/2011/04/industria-delaticinios-no-brasil.html. Acesso em: 01/07/2012.

EMBRAPA. CONTROLE SANITÁRIO DO REBANHO. Disponível em: http://www.cnpgc.embrapa.br/publicacoes/doc/doc71/controle.html. Acesso em: 06/06/2012.

COLDEBelLA, C. et al. Tratamento de Efluentes da Industria de Laticínios. Disponível em: http://pt.scribd.com/doc/67449818/55004822-Tratamento-de-Efluentes-Da-Industria-de-Laticinios. Acesso em: 18/06/2012.

FERREIRA, M. A. Principais pontos de contaminação do leite e implantação de boas práticas. Disponivel em: http://www.leite.pr.gov.br/arquivos/File/2sem/uel_marcia.pdf. Acesso em: 20/06/2012.

GOMES, S. T. Produção de leite no Brasil. Disponivel em: http://www.ufv.br/der/docentes/stg/stg_artigos/Art_051\%20\%20PRODU\%C7\%C3O\%20DE\%20LEITE\%20NO\%20BRASI L\%20(3-10-91).pdf. Acesso em: 20/06/2012.

IBGE. Estimativas preliminares para 10 de julho de 2011 . Disponível em: http://www.ibge.gov.br/home/estatistica/populacao/estimativa2011/estimativa.shtm. Acesso em: 22/06/2012.

JERÔNIMO, C. E. M., Valorização e Aproveitamento de Subprodutos Lácticos: Extração de Proteínas e Hidrogenação Catalítica da Lactose, Dissertação de mestrado, Depto de Eng. Química, UFRN, Natal, Brasil. (2003).

JERONIMO, C. E. M.; SANTIAGO JR, A. F. Desafios da Administração Ambiental Publica: Estudo de Caso do Municipio de Espirito Santo/RN. Revista de Administração de Roraima - RARR, Ed. 2, Vol. 1, p 136-146, Boa Vista, 1o Sem 2012.

MARAGNO, A. L. F. C., CAMPOS, J. R. Treatment of wastewater with a low concentration of organics using an anaerobic fluidized bed reactor. Water Science and Technology, Oxford, v.25, n.7, p.179-191, 1992.

PRINCE, A. A. et al. Controle Ambiental em Pequenos e Médios Laticínios de Minas Gerais - Uma Pesquisa Aplicada. In: 20 o Congresso da ABES. 1999. Rio de Janeiro - RJ.

ROHLFES, A. L . B. et al. Indústrias lácteas: alternativas de aproveitamento do soro de leite como forma de gestão ambiental. TECNO-LÓGICA, Santa Cruz do Sul, v.15, n.2, p.79-83, jul./dez. 2011.

SARAIVA, C. B.; PEReIRA, D. A. Diagnóstico Ambiental de um Laticínio de Pequeno Porte. Rev. Bras. De Agroecologia/nov. Vol. 4, No. 2. 2009.

SEBRAE. Como Montar uma Queijeira Padrão. SEBRAE. Natal - Brasil. 2002.

SEBRAE. Diagnóstico da indústria de laticínios do Estado de Minas Gerais. Belo Horizonte: SEBRAE, 1997, 270 p.

VOGELAAR, R. C.; PAWLOWSKY, U. Reaproveitamento do Soro do Queijo por Coagulação com Quitosana. In: 19o Congresso da ABES. 1997. Rio de Janeiro - RJ. 